\title{
The Efficacy and Safety of Evekeo, Racemic Amphetamine Sulfate, for Treatment of Attention-Deficit/Hyperactivity Disorder Symptoms: A Multicenter, Dose-Optimized, Double-Blind, Randomized, Placebo-Controlled Crossover Laboratory Classroom Study
}

\author{
Ann C. Childress, MD, Matthew Brams, MD, ${ }^{2}$ Andrew J. Cutler, MD, ${ }^{3}$ Scott H. Kollins, $\mathrm{PhD},{ }^{4}$ \\ Jo Northcutt, $\mathrm{PhD},{ }^{5}$ Americo Padilla, $\mathrm{MD},{ }^{6}$ and John M. Turnbow, $\mathrm{MD}^{7}$
}

\begin{abstract}
Objective: The study goal was to determine the efficacy and safety of an optimal dose of Evekeo, racemic amphetamine sulfate, 1:1 D-amphetamine and L-amphetamine (R-AMPH), compared to placebo in treating children with attention-deficit/ hyperactivity disorder (ADHD) in a laboratory classroom setting.

Methods: A total of 107 children ages 6-12 years were enrolled in this multicenter, dose-optimized, randomized, doubleblind, placebo-controlled crossover study. After 8 weeks of open-label dose optimization, 97 subjects were randomized to 2 weeks of double-blind treatment in the sequence of R-AMPH followed by placebo $(n=47)$ or placebo followed by R-AMPH $(n=50)$. Efficacy measures included the Swanson, Kotkin, Agler, M-Flynn, and Pelham (SKAMP) Rating Scale and Permanent Product Measure of Performance (PERMP) administered predose and at 0.75, 2, 4, 6, 8, and 10 hours postdose on 2 laboratory classroom days. Safety assessments included physical examination, chemistry, hematology, vital signs, and treatment-emergent adverse events (TEAEs).

Results: Compared to placebo, a single daily dose of R-AMPH significantly improved SKAMP-Combined scores $(p<0.0001)$ at each time point tested throughout the laboratory classroom days, with effect onset 45 minutes postdose and extending through 10 hours. R-AMPH significantly improved PERMP number of problems attempted and correct $(p<0.0001)$ throughout the laboratory classroom days. During the twice-daily dose-optimization open-label phase, improvements were observed with R-AMPH in scores of the ADHD-Rating Scale IV and Clinical Global Impressions Severity and Improvement Scales. TEAEs and changes in vital signs associated with R-AMPH were generally mild and not unexpected. The most common TEAEs in the open-label phase were decreased appetite (27.6\%), upper abdominal pain (14.3\%), irritability (14.3\%), and headache (13.3\%).
\end{abstract}

Conclusions: Compared to placebo, R-AMPH was effective in treating children aged 6-12 years with ADHD, beginning at 45 minutes and continuing through 10 hours postdose, and was well tolerated.

Trial registration: ClinicalTrials.gov identifier: NCT01986062. https://clinicaltrials.gov/ct2/show/NCT01986062

\footnotetext{
${ }^{1}$ Center for Psychiatry and Behavioral Medicine, Las Vegas, Nevada.

${ }^{2}$ Baylor College of Medicine, Houston, Texas.

${ }^{3}$ University of Florida and Florida Clinical Research Center, Bradenton, Florida.

${ }^{4}$ Department of Psychiatry and Behavioral Science, Duke University, Durham, North Carolina.

${ }^{5}$ Florida Clinical Research Center, LLC, Maitland, Florida.

${ }^{6}$ Miami Research Associates, South Miami, Florida.

${ }^{7}$ Westex Clinical Investigations, Lubbock, Texas.

Statistical analyses were performed by Rho, Inc. (Chapel Hill, North Carolina).

Funding: This study was funded by Arbor Pharmaceuticals (Atlanta, Georgia).
}

(C) Childress et al, 2015; Published by Mary Ann Liebert, Inc. This Open Access article is distributed under the terms of the Creative Commons Attribution Noncommercial License (http://creativecommons.org/licenses/by-nc/4.0/) which permits any noncommercial use, distribution, and reproduction in any medium, provided the original author(s) and the source are credited. 


\section{Introduction}

A TTENTION-DEFICIT/HYPERACTIVITY DISORDER (ADHD) is a common neurobehavioral disorder that presents in childhood and is characterized by pervasive and impairing symptoms of inattention, hyperactivity, and impulsivity [Diagnostic and Statistical Manual of Mental Disorders, 5th edition (DSM-5)] (American Psychiatric Association 2013). In the United States, the parentreported percentage of children aged 4-17 years ever diagnosed with ADHD is $11.0 \%$ (6.4 million children) (Visser et al. 2014). Worldwide, the prevalence of ADHD is estimated to be $5.9 \%-7.1 \%$ in children and adolescents and $5.0 \%$ in adults (Willcutt 2012). Without treatment, significant impairment in academic and social function can occur, often resulting in poor outcomes (Biederman et al. 2012). The most commonly employed medications for treating ADHD are stimulants, with usage supported by published guidelines of the American Academy of Child and Adolescent Psychiatry and the American Academy of Pediatrics (Pliszka 2007; Wolraich et al. 2011a, 2011b). This class of compounds includes various preparations of amphetamine or methylphenidate, which can effect rapid improvement in conduct, attentiveness, and academic performance (Barbaresi et al. 2007).

Amphetamines, also known as sympathomimetic amines, increase synaptic levels of the catecholamines dopamine and noradrenaline by inhibiting their reuptake into the neuron and also by releasing them into the synaptic cleft. Amphetamine contains a single chiral center that gives rise to distinct enantiomeric active forms-dextro (D)-amphetamine and levo (L)-amphetamine isomers. The two isomers have different pharmacokinetic properties (the mean elimination half-life is reported as ranging from 9.77 to 11 hours for D-amphetamine vs. 11.5 to 13.8 hours for L-amphetamine) and different neuropharmacological properties (Heal et al. 2013). While evidence is lacking regarding the specific mechanisms whereby amphetamines produce cognitive and behavioral effects in children and how those effects relate to the condition of the central nervous system, it is known that the mechanisms of action and effect profiles differ for the D- and L-amphetamine enantiomers and product formulations with different mixtures of the enantiomers (Hodgkins et al. 2012). In a pharmacologic analysis, Damphetamine had greater effects on dopamine than noradrenaline, while L-amphetamine had a more balanced action increasing both dopaminergic and noradrenergic neurotransmission; D-amphetamine is approximately twice as powerful a central stimulant as racemic amphetamine and three to four times as potent as L-amphetamine (Ghodse 2010). In animal models, D-amphetamine has been found to reduce overactivity and impulsiveness more efficiently than comparable doses of L-amphetamine, while the behavioral effects of L-amphetamine might be relatively more specific for improving sustained attention (Sagvolden and $\mathrm{Xu}$ 2008). Because it is a sympathomimetic drug, amphetamine can cause increased heart rate and blood pressure, palpitations, dilated pupils, dry mouth, and sweating; L-amphetamine has a greater effect on the cardiovascular system than D-amphetamine (Ghodse 2010).

Several amphetamine products for the treatment of ADHD have been developed with different proportions of each isomer. Some consist entirely of D-amphetamine. A currently available enantiomeric formulation consists of a ratio of 3:1 D-amphetamine to $\mathrm{L}$-amphetamine. The amphetamine sulfate product investigated in this study, Evekeo (Arbor Pharmaceuticals, Atlanta, GA), is a racemic enantiomeric formulation with a ratio of $1: 1 \mathrm{D}$-amphetamine to L-amphetamine (R-AMPH). R-AMPH is an immediate-release drug supplied as 5 and $10 \mathrm{mg}$ tablets.
The primary objective of the current study was to establish that an optimal dose of R-AMPH in children 6-12 years old diagnosed with ADHD would result in a significant reduction in ADHD signs and symptoms compared to placebo at 2 hours postdose in a laboratory classroom, while characterizing the onset of effect and duration of action for the medication. A laboratory classroom setting for study of ADHD medications allows for assessment by trained observers over the course of a typical extended school day, with both subjective and objective measures for determining onset and duration of drug effect (Wigal and Wigal 2006).

\section{Methods}

\section{Subjects}

Males and females between the ages of 6 and 12 years meeting DSM-IV-TR criteria for ADHD combined, inattentive, or hyperactive/ impulsive type were eligible for the trial. The diagnosis was confirmed during screening using the Mini International Neuropsychiatric Interview for Children and Adolescents (MINI-KID). Study inclusion required that subjects receive a score of at least 3 (mildly ill) on the clinician-administered Clinical Global Impressions-Severity (CGIS) scale and have an ADHD-Rating Scale (ADHD-RS-IV) score (DuPaul et al. 1998) at screening or baseline $\geq 90$ th percentile normative values for gender and age in at least one of the following categories: Hyperactive/impulsive subscale, inattentiveness subscale, or total score. The ADHD-RS-IV is an 18-item scale based on Diagnostic and Statistical Manual of Mental Disorders, 4th edition, Text Revision (DSM-IV-TR) (American Psychiatric Association 2000) criteria of ADHD that rates symptoms on a 4-point scale. Each item is scored using a combination of severity and frequency ratings from a range of 0 (reflecting no symptoms or a frequency of never or rarely) to 3 (reflecting severe symptoms or a frequency of very often), so that the total ADHD-RS-IV scores range from 0 to 54. The 18 items can be divided into two 9-item subscales: One for hyperactivity/impulsivity and the other for inattentiveness. Scores were obtained during a clinician-directed interview with the parent/ caregiver at each visit. The CGI-S is a clinician-rated scale that evaluates the severity of psychopathology (ADHD symptoms in this trial) on a scale from 1 (not at all ill) to 7 (among the most severely ill) (Busner and Targum 2007). To qualify for inclusion, the subject also had to be in need of pharmacological treatment for ADHD in the judgment of the site principal investigator.

A primary psychiatric diagnosis other than ADHD excluded a subject from participating in the study, as did secondary or co-morbid diagnoses other than ADHD with the exception of simple phobias, oppositional defiant disorders, motor skill disorders, communication disorders, learning disorders, adjustment disorders, and sleep disorders. Subjects with a clinically significant cognitive impairment or a personal history of seizure disorder (except simple febrile seizures), untreated thyroid disease, glaucoma, Gilles de la Tourette's disorder, or chronic tics were excluded from participating in the study. Also excluded were subjects with a personal history of structural cardiac disorders, serious cardiac conditions, or severe hypertension. Those subjects with a family history of sudden cardiac death required review and approval by the medical monitor before being cleared for participation in the study. Taking an investigational drug within 60 days of the screening visit was also exclusionary.

\section{Study design}

This multicenter, dose-optimized, double-blind, randomized, placebo-controlled crossover study was conducted to evaluate the 
safety and efficacy of R-AMPH in pediatric subjects aged 6-12 years with ADHD. A laboratory school protocol, as described by Wigal and Wigal (2006), was used to measure the efficacy, onset of effect, and duration of effect. The study was conducted at seven sites in the United States, in accordance with Good Clinical Practice guidelines. The study was approved by an appropriate institutional review board at each study site.

The study design is outlined in Figure 1. At the screening visit (study visit 1), before the performance of any study-specific procedures, each subject and his or her parent/guardian received an explanation of all study procedures, and the parent/guardian provided voluntary written informed consent for the subject to participate in this study, and the subject gave written assent. Screening assessments were then administered to determine eligibility. Medical history, including medications, was reviewed. A physical examination was performed, with vital signs (sitting blood pressure and pulse, in triplicate via automated machine, along with respiratory rate and temperature), 12-lead electrocardiogram (ECG) (performed at screening only), and laboratory tests, including serum chemistry panel, hematology, urinalysis, and urine screen for commonly abused drugs. Female subjects of childbearing potential were administered a serum pregnancy test.

At the baseline visit, the subject's medical history was reviewed again, body weight was obtained, and sitting blood pressure and pulse were again measured in triplicate. A urine pregnancy test was obtained in female subjects of childbearing potential. The ADHDRS-IV, CGI-S, Conners 3rd Edition Parent Short Form (Conners 3-P), and baseline version Columbia-Suicide Severity Rating Scale (C-SSRS) were also administered. The Conners 3-P is a 45-item parent (or guardian) report that provides evaluation of inattention, hyperactivity/impulsivity, learning problems, executive functioning, aggression, and peer relationships. Subjects meeting all eligibility requirements were prohibited from using any psychotropic medications with the exception of sedative hypnotics prescribed as sleep aids during the trial. Anticonvulsants, antidepressants, antipsychotics, or nonstimulant ADHD medications (atomoxetine, guanfacine, or clonidine) were not allowed within the 30 days before the baseline visit and for the duration of the study. Stimulant medications were allowed until 24 hours before the baseline visit. Other medications allowed during the course of the study included acetaminophen and nonsteroidal anti-inflammatories; nonsedating antihistamines such as cetirizine, loratadine, and fexofenadine; mometasone; and approved courses of prescription and nonprescription medications for the treatment of acute illnesses.

The baseline visit (study visit 2, study day 1) occurred within 30 days following the screening visit. During this visit, subjects were reassessed for eligibility and administered a placement Permanent Product Measure of Performance (PERMP), an objective individualized mathematics examination, to assign the level of difficulty that would be administered throughout the laboratory classroom segment of the study as an objective measurement of efficacy. Subjects meeting all eligibility requirements, including performance at the basic level of the PERMP or higher, were enrolled in the study. Open-label medication was dispensed to the subjects, who were instructed to start taking the medication twice daily (once in the morning with or without food and again 4-6 hours later), beginning on the following morning, study day 2 , and continuing through approximately study day 50 . The starting dose of R-AMPH for the 8-week open-label dose-titration period of the study was $10 \mathrm{mg}$ per day ( $5 \mathrm{mg}$ twice daily), which was titrated weekly in $5 \mathrm{mg}$ increments until an optimal dose based on clinical response and tolerability was achieved in the judgment of the site principal investigator. A single down-titration for tolerability reasons was also permitted. To globally assess changes in the severity of ADHD from visit to visit over the course of the open-label phase of the study, clinicians used the ADHD-RS-IV, CGI-S, and Clinical Global Impressions-Improvement (CGI-I). The CGI-I is scored from 1 (very much improved) to 7 (very much worse). The parent/ guardian assessed changes in ADHD symptoms via the Conners 3-P performed on study visits 6 (after week 4) and 10 (after week 8). Safety and tolerability were assessed via weekly monitoring of subject blood pressure and pulse and the tracking of spontaneously reported adverse events. The C-SSRS was also used to assess changes from baseline in the occurrence and severity of suicidal ideation and behavior.

At study visit 10, subjects able to tolerate a stable dose of at least $10 \mathrm{mg}$ per day were randomized on a 1:1 basis by an interactive webbased response system (IWRS) to a treatment sequence of 1 week RAMPH/1 week placebo or 1 week placebo/1 week R-AMPH. The crossover design allowed subjects to serve as their own controls.

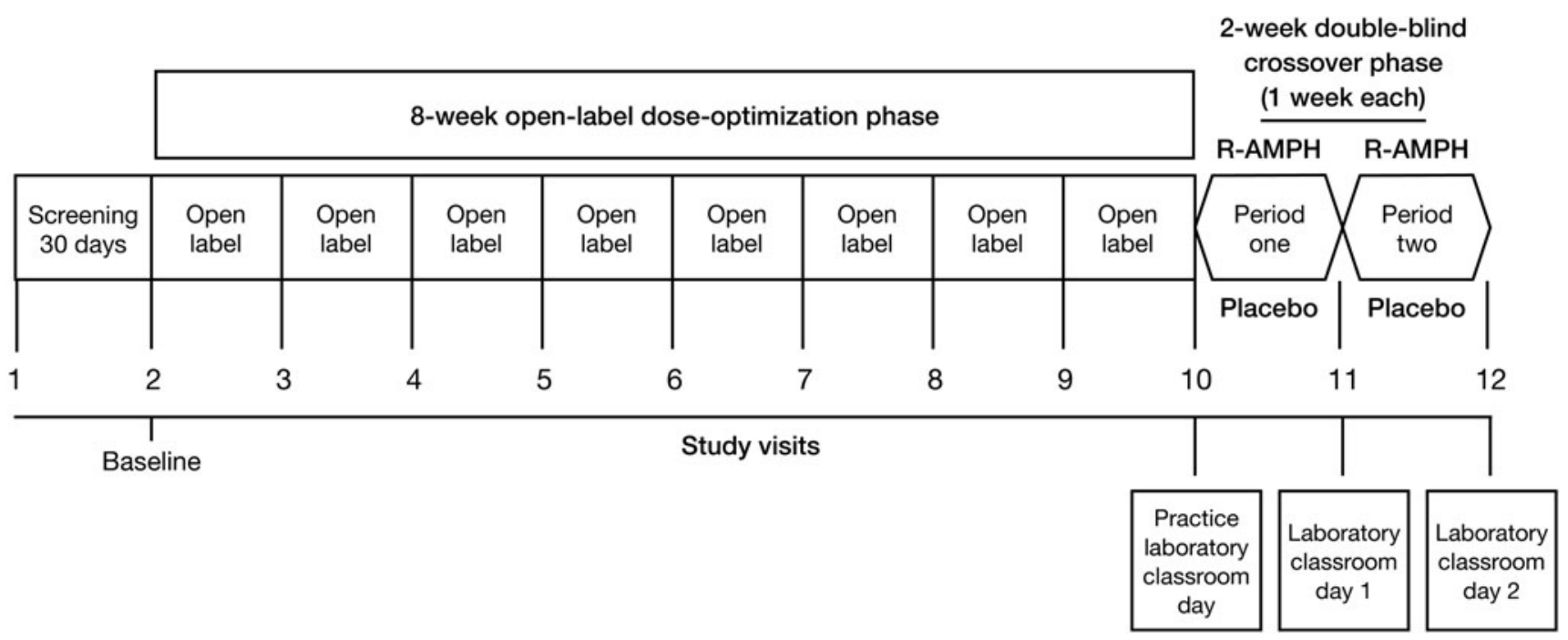

FIG. 1. R-AMPH laboratory classroom trial design. 
At study visit 10, each subject completed an abbreviated practice laboratory classroom session lasting $\sim 4$ hours and was dispensed the first week of double-blind study medication, which was to be taken twice daily, at home and/or school, for the following 6 days. No adjustment of R-AMPH dose was permitted during the doubleblind phase. The final dose of the first week of double-blind medication was administered at the laboratory school site by study staff on the morning of the first full-length laboratory classroom day (study visit 11). On the 2 full laboratory classroom days, only the single morning dose was administered (and not the second daily dose), to establish duration of action of the racemic formulation. At the end of study visit 11 , double-blind crossover medication, to be taken at home and/or school twice daily for the following 6 days during the second week of the double-blind phase, was dispensed. The final dose of crossover medication was administered at the laboratory school site by study staff on the morning of the second full-length laboratory classroom day (study visit 12).

One week following study visit 12 , a final safety assessment was conducted during a postwithdrawal follow-up phone call or visit to the study site.

\section{Outcome measures: Efficacy}

The primary objective of the study was to establish that an optimal dose of R-AMPH would result in a significant reduction in ADHD signs and symptoms compared to placebo at 2 hours postdose. The secondary efficacy objectives were to determine the onset and duration of clinical effect for R-AMPH after a single morning dose. Primary and secondary efficacy analysis variables were measured in a laboratory classroom setting that was designed to model a typical school day plus after-school activity totaling 10 hours. The primary efficacy variable was the Swanson, Kotkin, Agler, M-Flynn, and Pelham (SKAMP)-Combined score determined at 2 hours postdose on the 2 full-length laboratory classroom days (visits 11 and 12). The SKAMP scale is a validated subjective measure of ADHD symptoms in a laboratory classroom. It comprised 13 items (grouped under the subcategories of attention, deportment, quality of work, and compliance) on which subjects were rated according to a 7 -point scale $(0=$ normal to $6=$ maximal impairment) by trained study personnel (Wigal and Wigal 2006). The SKAMP-Combined score was obtained by summing the rating values for each of the 13 items. Higher SKAMP scores signified greater impairment.

The secondary efficacy variables included SKAMP-Combined scores, SKAMP-Attention subscale scores (four items), SKAMPDeportment subscale scores (four items), and PERMP scores, each measured before dosing and at $0.75,2,4,6,8$, and 10 hours postdose on the 2 full-length laboratory classroom days. The PERMP is an individualized, five-page mathematics examination consisting of 400 problems. Subjects were instructed by site staff to work at their seats and complete as many problems as possible in $10 \mathrm{~min}-$ utes. The appropriate level of difficulty for each student was determined based on the results of the PERMP administered at the baseline visit. Performance was evaluated using two scores: The number of problems attempted (PERMP-A) and the number of problems correct (PERMP-C). Additional secondary efficacy variables included the CGI-S, CGI-I, and ADHD-RS-IV ratings obtained during the open-label phase of the study.

\section{Outcome measures: Safety}

The secondary safety objective was to investigate the safety and tolerability of R-AMPH compared to placebo in pediatric subjects
6-12 years of age diagnosed with ADHD. The occurrence of treatment-emergent adverse events (TEAEs) was assessed starting at visit 3 (following the first week of the open-label dose-optimization phase of the study) and ending with the postwithdrawal follow-up phone call. Additional safety evaluations included physical examination, with blood pressure and pulse measured in triplicate, as well as height and weight, repeat laboratory tests, and a follow-up C-SSRS administered at each study visit.

\section{Statistical analyses}

Primary and secondary efficacy analyses were performed on the intent-to-treat (ITT) population consisting of all randomized subjects who received at least one dose of double-blind study medication and had at least one postbaseline assessment of the primary efficacy variable. The key secondary efficacy analysis was repeated on the clinically evaluable population, defined as all ITT subjects who received the morning dose of double-blind study medication at both laboratory test sessions; completed all laboratory classroom tests; did not miss more than 2 days of therapy during the doubleblind treatment period; and did not use prohibited medication during the double-blind treatment period. Descriptive statistics for the SKAMP-Combined, SKAMP-Attention, SKAMP-Deportment, PERMP-A, and PERMP-C scores were calculated for each time point on the laboratory classroom days. The average difference between treatments (R-AMPH vs. placebo) was estimated for each variable using least-square (LS) means from a mixed-effects repeated-measures model, including treatment, sequence, period, and study center as fixed effects, and subject within sequence as a random effect. The treatment comparison was conducted as a twosided test at the 5\% level of significance. Standard errors and $95 \%$ confidence intervals (CIs) were calculated. All available data were used; there was no imputation of missing data. Descriptive statistics and changes from baseline were calculated for the additional secondary efficacy variables, including CGI-S, CGI-I, and ADHDRS-IV, obtained during the open-label phase of the study. Also determined for ADHD-RS-IV was the proportion of responders, defined as subjects who had a $\geq 50 \%$ change from baseline.

Analyses were performed on both the enrolled safety population (defined as all enrolled subjects who received at least one dose of open-label study medication and had at least one postbaseline safety assessment) and the randomized safety population (defined as all randomized subjects who received at least one dose of doubleblind study medication and had at least one postbaseline safety assessment). The frequencies of adverse events (AEs), the results of laboratory assessments and physical examinations (including vital signs), and the frequency of suicidal ideation or behavior (assessed using the C-SSRS) were summarized descriptively by the treatment group.

\section{Results}

\section{Subject disposition}

Subject disposition is summarized in Figure 2. Of 107 subjects enrolled in the 8-week open-label phase of the study, 10 withdrew before randomization, leaving 97 subjects for the ITT population and for the randomized safety population -47 subjects randomized to the treatment sequence of R-AMPH followed by placebo and 50 to the sequence of placebo followed by R-AMPH. Two randomized subjects completed only one of the two double-blind period laboratory classroom days - one subject was unable to come for the second laboratory classroom day, and one was lost to follow-up. 
107 patients enrolled in 8-week open-label phase

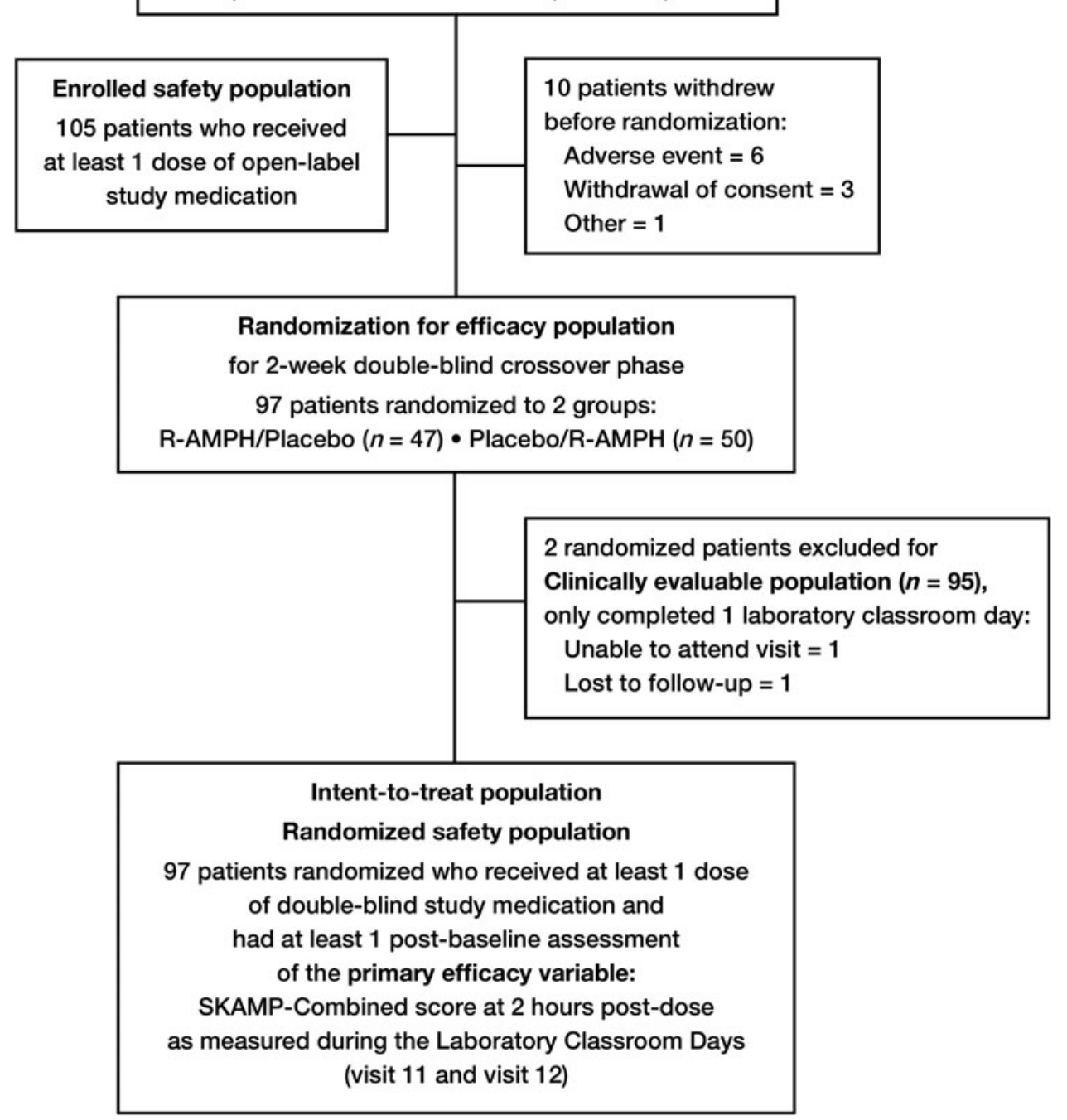

FIG. 2. Subject disposition in the R-AMPH laboratory classroom study.

Therefore, the clinically evaluable population for repeat analyses of the primary and secondary efficacy variables consisted of 95 subjects $(97.94 \%)$ from the ITT population. The enrolled safety population for analyzing safety data across the entire study consisted of 105 of the 107 total enrolled subjects. One subject not included withdrew prematurely due to an AE (irritability) after receiving the study drug but before having any postbaseline safety assessments; the other subject was discontinued at the discretion of the investigator, also without having any postbaseline safety assessments.

The demographic and baseline characteristics of the ITT population are shown in Table 1. The majority of subjects were male $(60.8 \%)$ and white $(59.8 \%)$. Mean subject age was $9.6 \pm 1.86$ years, with $16.5 \%$ aged $6-7$ years, $45.4 \%$ aged $8-10$ years, and $38.1 \%$ aged 11-12 years. Most subjects $(81.4 \%)$ were diagnosed with combined type ADHD, while $18.6 \%$ were diagnosed with the inattentive type, and no subjects with strictly hyperactive/impulsive type. All 97 subjects had symptoms $\geq$ ADHD-RS-IV 90th percentile at baseline. At screening, 91 subjects $(86.7 \%)$ had normal ECG findings and 14 subjects (13.3\%) had abnormal ECG findings, none of which was recorded as being clinically significant. Medical history and prior medication usage were similar between the R-AMPH/placebo and placebo/R-AMPH groups, the most frequent findings being asthma (21.9\%), seasonal allergy (10.5\%), drug hypersensitivity (8.6\%), and oppositional defiant disorder $(8.6 \%)$. The most frequently reported prior medications were centrally acting sympathomimetics $(48.6 \%)$. During the study, for the enrolled safety population, the most frequently administered concomitant medications were centrally acting sympathomimetics $(35.2 \%)$, selective beta-2-adrenoreceptor agonists (17.1\%), propionic acid derivatives $(15.2 \%)$, and other antihistamines for systemic use $(12.4 \%)$.

\section{Efficacy assessments: Primary measure}

The primary efficacy variable was the SKAMP-Combined score determined at 2 hours postdose on the 2 full-length laboratory classroom days (visits 11 and 12). R-AMPH demonstrated significant improvement on the SKAMP-Combined scores at 2 hours postdose compared to placebo at visits 11 and 12 for the ITT population (Table 2). The LS mean SKAMP-Combined score was 10.3 in subjects receiving R-AMPH compared with 18.1 in those receiving placebo. The LS mean treatment difference (R-AMPH 
Table 1. Subject Demographics AND BASELINe CharaCteristics

\begin{tabular}{|c|c|c|c|}
\hline \multirow[b]{3}{*}{ Characteristics } & \multirow{3}{*}{$\begin{array}{c}\begin{array}{c}8 \text {-week } \\
\text { open label } \\
(\mathrm{n}=97)\end{array} \\
\mathrm{n}(\%)\end{array}$} & \multicolumn{2}{|c|}{ 2-week crossover study } \\
\hline & & \multirow{2}{*}{$\begin{array}{c}\begin{array}{c}R-A M P H / \\
\text { Placebo } \\
(\mathrm{n}=47)\end{array} \\
\mathrm{n}(\%)\end{array}$} & \multirow{2}{*}{$\begin{array}{c}\begin{array}{c}\text { Placebo/ } \\
R-A M P H \\
(\mathrm{n}=50)\end{array} \\
\mathrm{n}(\%)\end{array}$} \\
\hline & & & \\
\hline Age (years, mean \pm SD) & $9.6 \pm 1.86$ & $9.6 \pm 1.97$ & $9.6 \pm 1.78$ \\
\hline $6-7$ & $16(16.5)$ & 7 (14.9) & $9(18.0)$ \\
\hline $8-10$ & $44(45.4)$ & $22(46.8)$ & $22(44.0)$ \\
\hline $11-12$ & $37(38.1)$ & $18(38.3)$ & $19(38.8)$ \\
\hline \multicolumn{4}{|l|}{ Gender } \\
\hline Male & $59(60.8)$ & $29(61.7)$ & $30(60.0)$ \\
\hline Female & $38(39.2)$ & $18(38.3)$ & $20(40.0)$ \\
\hline \multicolumn{4}{|l|}{ Race } \\
\hline White & $58(59.8)$ & $30(63.8)$ & $28(56.0)$ \\
\hline $\begin{array}{l}\text { Black/African } \\
\text { American }\end{array}$ & $33(34.0)$ & $13(27.7)$ & $20(40.0)$ \\
\hline Asian & $1(1.0)$ & $1(2.1)$ & 0 \\
\hline Other & $5(5.1)$ & $3(6.4)$ & $2(4.0)$ \\
\hline \multicolumn{4}{|l|}{ ADHD type } \\
\hline Inattentive & $18(18.6)$ & $9(19.1)$ & $9(18.0)$ \\
\hline $\begin{array}{c}\text { Hyperactive/ } \\
\text { impulsive }\end{array}$ & 0 & 0 & 0 \\
\hline Combined & $79(81.4)$ & $38(80.9)$ & $41(82.0)$ \\
\hline $\begin{array}{l}\text { Height at screening } \\
\quad(\text { in, mean } \pm \text { SD) }\end{array}$ & $55.16 \pm 5.4$ & $54.80 \pm 5.4$ & $55.49 \pm 5.4$ \\
\hline $\begin{array}{l}\text { Weight at baseline } \\
\quad(\mathrm{lbs}, \text { mean } \pm \text { SD) }\end{array}$ & $84.60 \pm 31.1$ & $82.20 \pm 30.2$ & $86.85 \pm 32.0$ \\
\hline
\end{tabular}

ADHD, attention-deficit/hyperactivity disorder; SD, standard deviation.

vs. placebo) was $-7.9(p<0.0001)$. A difference in LS means for the change from predose SKAMP-Combined scores also favored R-AMPH treatment compared to placebo for the primary outcome: -10.5 points $(95 \% \mathrm{CI}-13.2,-7.8 ; p<0.0001)$. When the primary efficacy analysis was repeated on data from the clinically evaluable population $(n=95)$, the results were similar to those observed for the ITT population. In a series of subgroup analyses on the primary efficacy endpoint, statistically significant differences in LS means favoring R-AMPH treatment over placebo were observed regardless of the final daily dose (10-15, 20-25, 30-35, $40 \mathrm{mg})$, subject age, gender, race, or ADHD type.

Table 2. Summary of SKAMP-Combined Scale at 2 Hours Postdose (ITT Population)

\begin{tabular}{lccc}
\hline Statistic & $\begin{array}{c}R-A M P H \\
(\mathrm{n}=97)\end{array}$ & $\begin{array}{c}\text { Placebo } \\
(\mathrm{n}=97)\end{array}$ & $\begin{array}{c}\text { Treatment } \\
\text { difference } R \text {-AMPH } \\
\text { vs. placebo }\end{array}$ \\
\hline$n$ & 95 & 97 & \\
Mean (SD) & $10.0(8.24)$ & $17.8(1.94)$ & \\
Median (Q1, Q3) & $8.0(5,12)$ & $15.0(8,24)$ & \\
Min, max & 0,48 & 1,52 & $-7.9(1.14)$ \\
LS mean (SE) & $10.3(1.09)$ & $18.1(1.09)$ & $-10.1,-5.6$ \\
95\% CI & $8.1,12.4$ & $16.0,20.2$ & $<0.0001$ \\
$p$-Value & & & $<$ \\
\hline
\end{tabular}

CI, confidence interval; ITT, intent-to-treat; LS, least squares; Q, quartile; SE, standard error; SKAMP, Swanson, Kotkin, Agler, M-Flynn, and Pelham Rating Scale.

\section{Efficacy assessments: Secondary measures}

Figure 3 shows the SKAMP-Combined scores over the course of the 2 laboratory classroom days-during which, overall, each subject received R-AMPH and placebo. Significant separation from placebo occurred at each time point tested $(0.75,2,4,6,8$, and 10 hours) ( $p<0.0001$ for all time points), with onset of R-AMPH effect by 45 minutes postdose (difference in LS means of -5.5 points) and with the greatest R-AMPH effect seen at 4 hours postdose (difference in LS means of -8.3 points). R-AMPH was still effective at 10 hours postdose (difference in LS means of -4.3 points), the last time point measured. The duration of the R-AMPH effect was therefore at least 9.25 hours (from 0.75 hours to the end of the study at 10 hours). Statistically significant differences $(p<0.0001)$ in LS means for the change from predose SKAMPCombined scores also favored R-AMPH treatment compared to placebo at each postdose time point, with the greatest change from baseline in R-AMPH treatment occurring at 2 hours postdose. When postdose SKAMP-Combined scores were analyzed by clinical site for the ITT population, the differences in LS means favored R-AMPH treatment at all time points for all sites. When SKAMPCombined scores were examined across different subgroups (final dose, subject age, gender, race, ADHD type), statistically significant differences in LS means favoring R-AMPH treatment over placebo were observed at each time point through 10 hours postdose, with results similar to those for the ITT population as a whole.

Results for the SKAMP-Attention and SKAMP-Deportment subscale scores were similar to those for the SKAMP-Combined scores, with 2-hour postdose differences in LS means favoring RAMPH treatment of -1.6 points on the SKAMP-Attention subscale and -2.5 points on the SKAMP-Deportment subscale. At each time point tested, significant separation of R-AMPH from placebo was observed for both the SKAMP-Attention and SKAMPDeportment subscales, again with the greatest R-AMPH effect seen at 4 hours postdose $(-1.8$ points for the SKAMP-Attention subscale and -2.6 points for the SKAMP-Deportment subscale) and the greatest change from predose score seen at 2 hours postdose (differences in LS means of - 1.4 points for the SKAMP-Attention subscale and -1.9 points for the SKAMP-Deportment subscale). Statistical significance was robust $(p<0.0001)$ for both subscales for all but two of the time point observations ( $p=0.0188$ at 10 hours for attention and $p=0.0018$ at 6 hours for deportment).

When subjects received R-AMPH, they attempted more problems on the PERMP and answered more of those questions correctly than when they received placebo. At each time point tested in the laboratory classroom setting $(0.75,2,4,6,8$, and 10 hours), both the number of problems attempted (Fig. 4) and the number of problems answered correctly on the PERMP (Fig. 5) were significantly higher ( $p<0.0001$ in all cases) after subjects received R-AMPH. While the greatest R-AMPH effect was seen at 4 hours postdose for the number of problems attempted (difference in LS means of 27.9 problems attempted) and at 2 hours postdose for the number of problems correct (difference in LS means of 28.0 problems correct), similar effect levels were seen between 2 and 6 hours for both categories (range of differences in LS means of 26.3 to 27.9 problems attempted and 24.9 to 28.0 problems correct). When PERMP scores were examined across the different subgroups (final dose, subject age, gender, race, ADHD type) with regard to the number of problems attempted and the number of problems correct, statistically significant differences in LS means favoring R-AMPH treatment over placebo were observed at each time point through 10 hours postdose, with trends similar to those for the ITT population as a whole. 


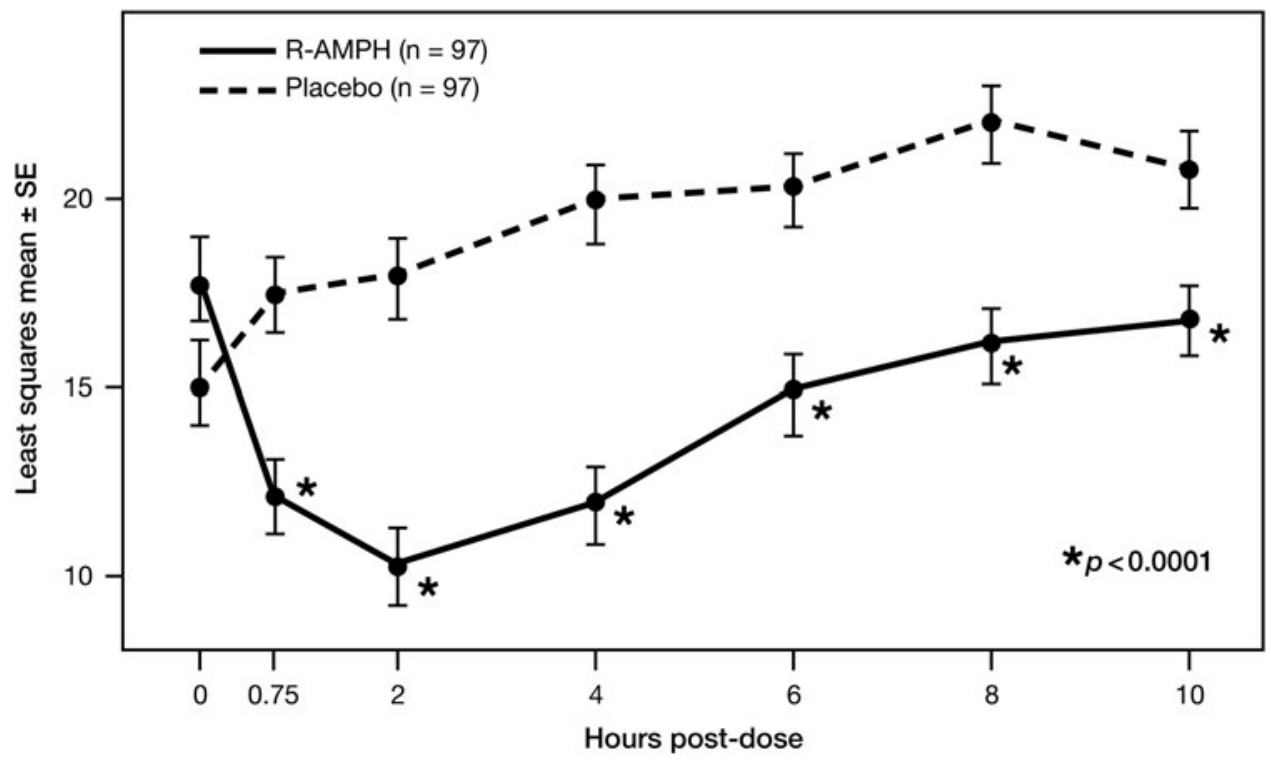

FIG. 3. Laboratory classroom SKAMP-Combined scores. SKAMP, Swanson, Kotkin, Agler, M-Flynn, and Pelham.

\section{Efficacy assessments: Secondary measures during the open-label phase}

During the open-label dose-titration period, mean (standard deviation [SD]) ADHD-RS-IV total scores decreased (improved) from 40.8 (7.64) at baseline to 13.0 (7.32) at the end of the 8-week study period (Fig. 6). Mean (SD) changes from baseline showed improvement of ADHD symptoms at each visit through the 8 weeks: From -7.4 (8.91) at week 1 to -27.8 (8.95) at week 8 for total score, from -3.8 (4.93) to -14.1 (5.54) for hyperactivity/ impulsivity score, and from $-3.5(4.73)$ to -13.7 (5.06) for inattentiveness score. Eighty-five subjects $(87.6 \%)$ were considered responders, defined as $\geq 50 \%$ improvement in the ADHD-RS-IV total score by that time point. When ADHD-RS-IV total scores were analyzed by subject age, gender, and race, mean changes from baseline showed improvement of ADHD symptoms over time through at least week 7 of the open-label phase, with results similar to those for the ITT population as a whole.

At the screening visit, $49.5 \%$ of subjects were considered moderately ill, as rated by the CGI-S score of $4 ; 37.1 \%$ were considered markedly ill (CGI-S score of 5) and $10.3 \%$ were considered severely ill (CGI-S score of 6). Only $3.1 \%$ of subjects were considered mildly ill (CGI-S score of 3). By the end of the 8-week open-label phase, $33.0 \%$ of subjects were considered normal, not at all ill (CGI-S score of 1), 26.8\% were borderline ill (CGI-S score of 2), $37.1 \%$ were mildly ill, $3.1 \%$ were moderately ill, and no subjects were classified as markedly or severely ill. Mean (SD) CGI-S scores decreased from $4.6(0.70)$ at baseline to $2.1(0.91)$ by the end of the open-label phase (Fig. 7). Based on the CGI-I measure of disease improvement relative to baseline, subjects continued to

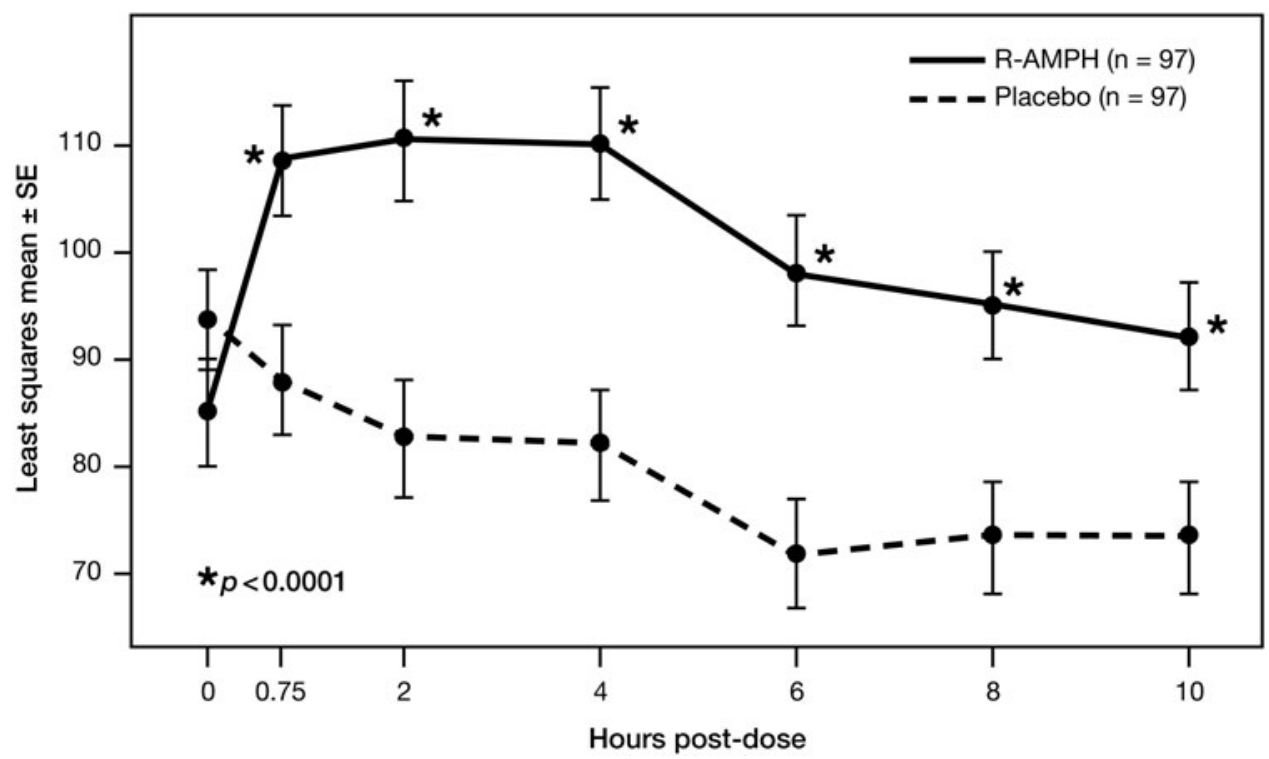

FIG. 4. PERMP number of problems attempted over time by treatment group. PERMP, Permanent Product Measure of Performance. 


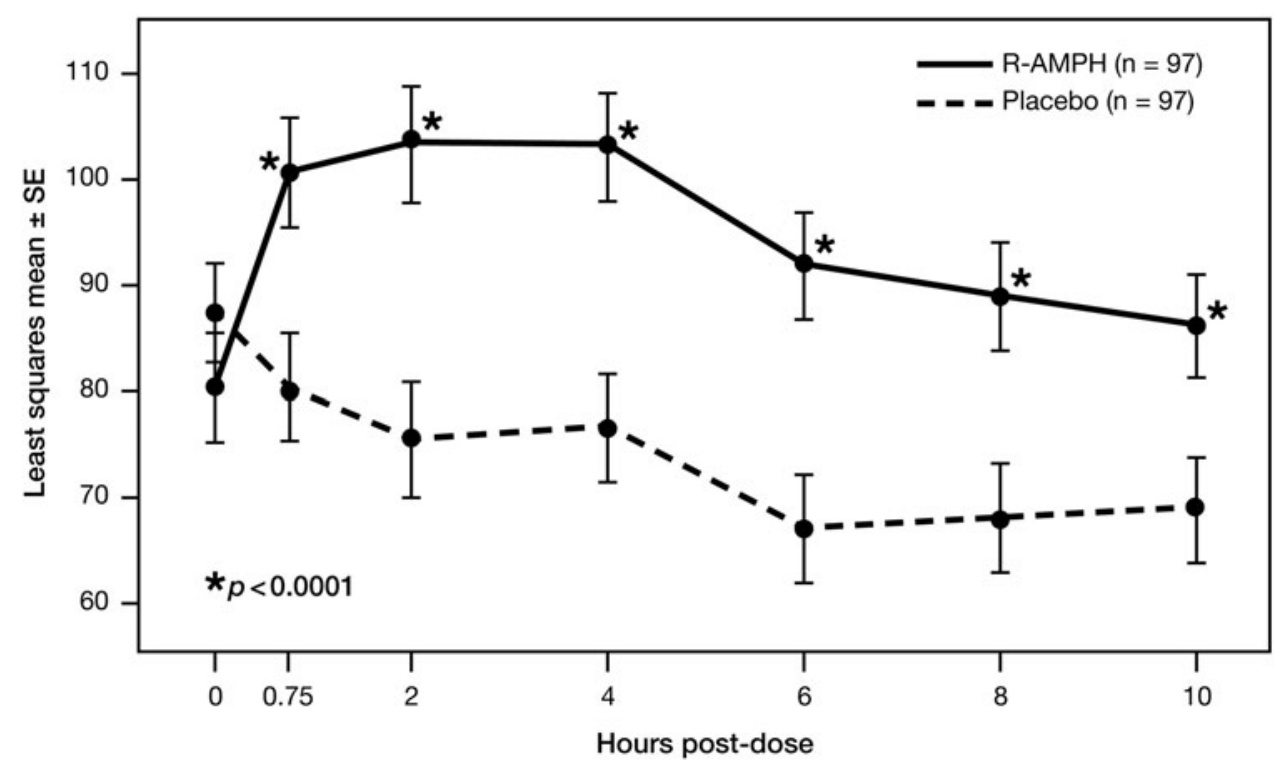

FIG. 5. PERMP number of problems correct over time by treatment group. PERMP, Permanent Product Measure of Performance.

improve throughout the 8 -week open-label phase. By week 4, $100 \%$ of subjects showed improvement $(42.3 \%$ very much improved, $42.3 \%$ much improved, and $15.5 \%$ minimally improved). By week $8,71.1 \%$ were very much improved, $23.7 \%$ were much improved, and 5.2\% were minimally improved (Fig. 8). Mean (SD) CGI-I scores improved from $3.3(0.94)$ at the end of open-label week 1 to $1.3(0.58)$ at the end of open-label week 8 .

Using the Conners 3-P for parent/guardian assessment, baseline scores were above average (worse) for the categories of inattention, hyperactivity/impulsivity, learning problems, executive functioning, aggression, and peer relationships. Mean (SD) improvements from baseline were observed at week 4 for each of the individual Conners
3-P categories and these improvements continued through week 8: Inattention - 16.6 (14.75) at week 4 and -22.0 (16.72) at week 8, hyperactivity/impulsivity -15.6 (14.54) and -23.3 (15.63), learning problems -8.3 (9.51) and -13.7 (12.39), executive function -16.4 (14.03) and -21.4 (14.84), aggression -7.6 (13.81) and -12.1 (16.15), and peer relationships -7.5 (18.23) and -11.9 (19.87).

\section{Safety assessment}

Ninety-six (91.4\%) of the 105 subjects in the enrolled safety population were exposed to R-AMPH for $>56$ days during the study. The mean (SD) length of exposure to the study medication

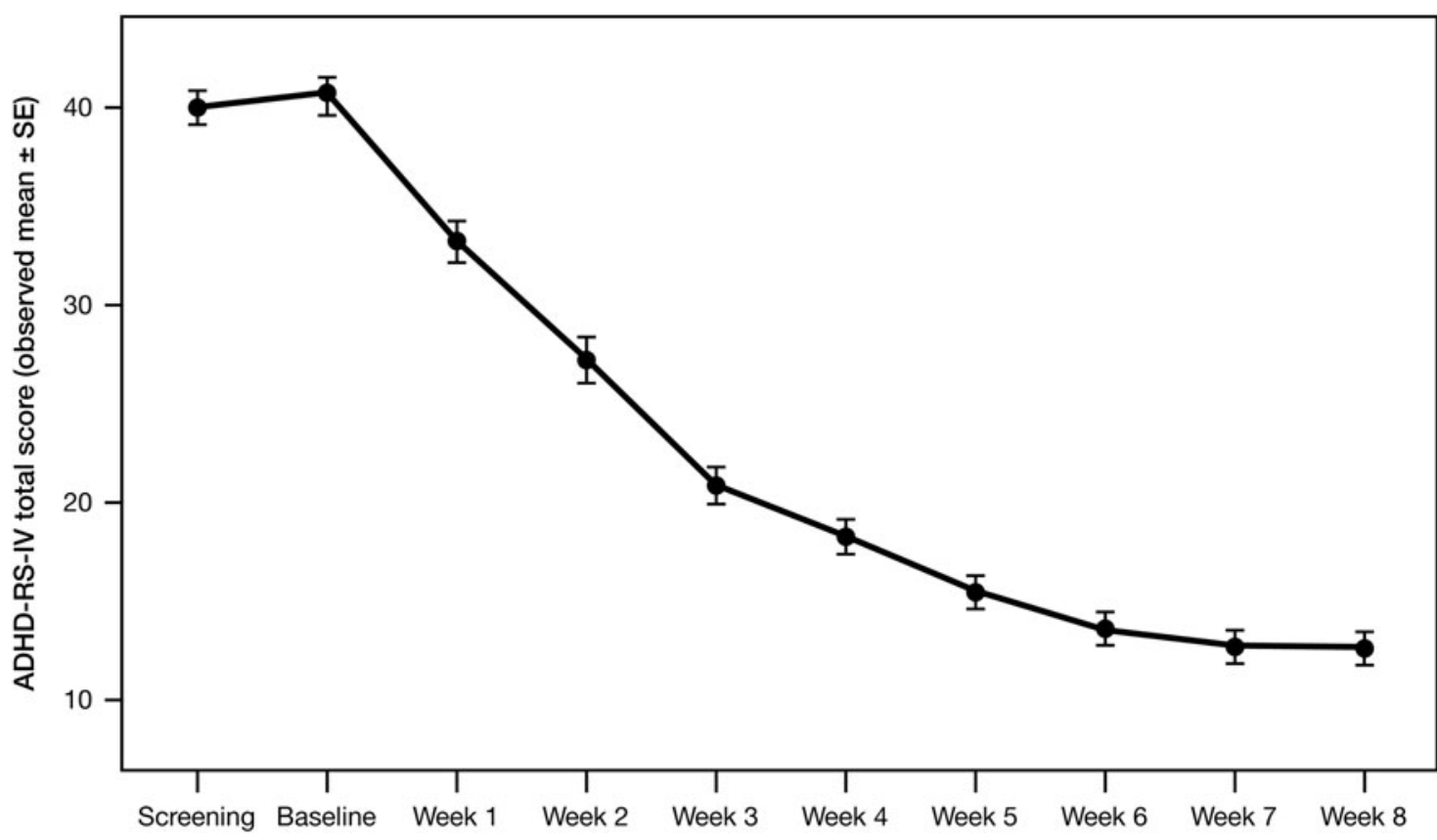

FIG. 6. Mean (SE) ADHD-RS-IV total scores in the open-label phase of the study. ADHD-RS-IV, ADHD-Rating Scale IV. 
6

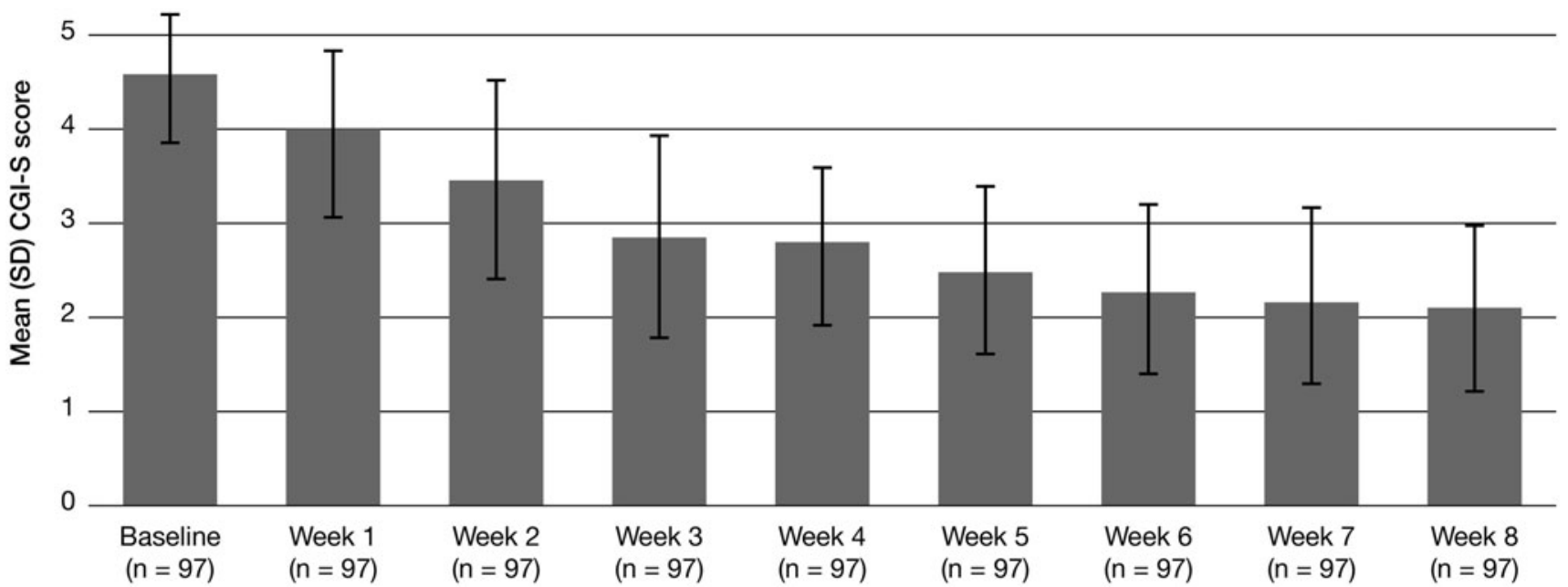

FIG. 7. Mean (SD) CGI-S scores in the open-label phase of the study. The CGI-S classifies current disease state as follows: $1=$ normal, not at all ill; $2=$ borderline ill; $3=$ mildly ill; $4=$ moderately ill; $5=$ markedly ill; $6=$ severely ill; $7=$ among the most extremely ill subjects; CGI-S, Clinical Global Impressions-Severity.

was 60.2 (11.73) days, with 53.9 (10.03) days during the open-label phase and 7.0 (0.23) days during the double-blind crossover phase. The mean (SD) daily dose of R-AMPH was 16.7 (4.77) $\mathrm{mg}$ for the enrolled safety population and 17.2 (4.55) $\mathrm{mg}$ for the randomized safety population (double-blind phase). The mean (SD) and median final dose for the randomized safety population were $23.4(8.18) \mathrm{mg}$ and $20.0 \mathrm{mg}$, respectively.

Of the 105 subjects in the enrolled safety population, 69 (65.7\%) experienced a total of 253 TEAEs during the open-label phase of the study (Table 3 ) and 59 (56.2\%) experienced treatment-related AEs. The most commonly experienced TEAE was decreased appetite $(27.6 \%$ of subjects, all judged by the investigator to be treatment related), followed by upper abdominal pain $(14.3 \%$, $13.3 \%$ treatment related) and irritability $(14.3 \%, 11.4 \%$ treatment related). Severe TEAEs were reported for two subjects (1.9\%) during the open-label phase: Initial severe insomnia, considered by the investigator to be related to the study drug, which lasted for 10 days and resulted in premature discontinuation; and severe insomnia, considered related to the study drug, which lasted for 1 day. No serious AEs or deaths were reported during the study. In the enrolled safety population, five subjects $(4.8 \%)$ had TEAEs that led to premature discontinuation of study drug (irritability, affect lability, initial insomnia, acarodermatitis, and rash, each experienced by a different one of the five subjects). An additional enrolled subject withdrew from the study before randomization due to an adverse event (irritability), but this subject was not included in the enrolled safety population due to the absence of any postbaseline safety assessment.

The occurrence of TEAEs in the randomized safety population during the double-blind crossover treatment phase is summarized in Table 4. The most frequently reported TEAEs were similar to those observed during the open-label treatment for the enrolled

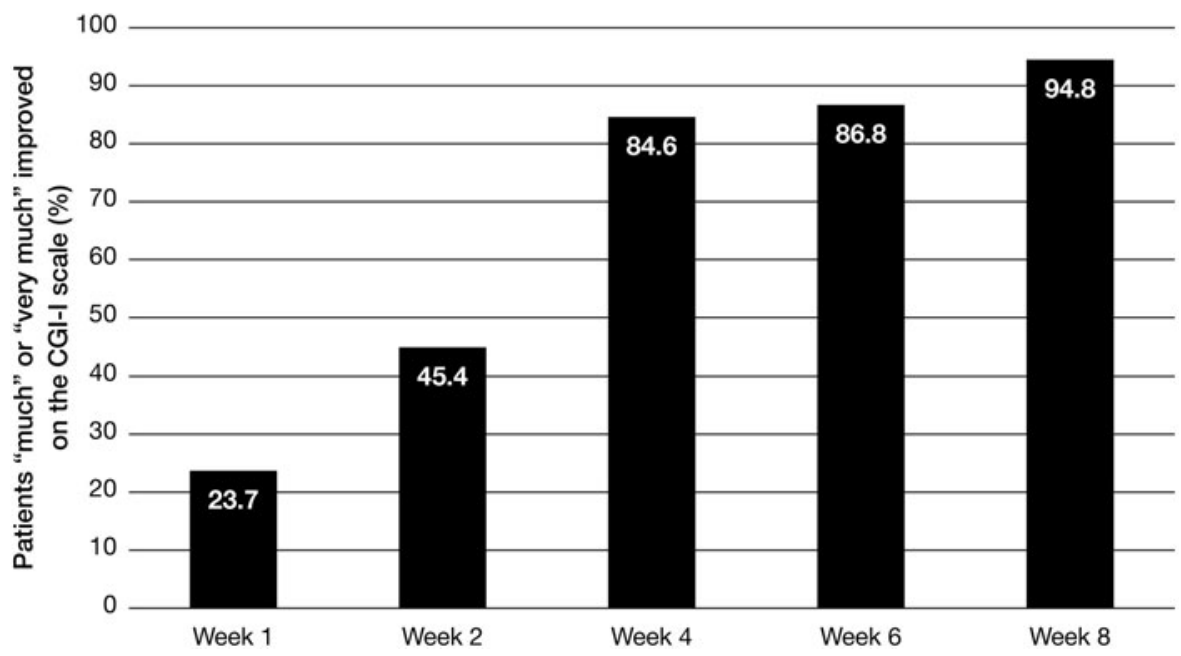

FIG. 8. Percentage of subjects either "much" or "very much" improved based on the CGI-I scale in the open-label phase of the study. The CGI-I classifies subject improvement as follows: $1=$ very much improved; $2=$ much improved; $3=$ minimally improved; $4=$ no change; $5=$ minimally worse; $6=$ much worse; $7=$ very much worse; CGI-I, Clinical Global Impressions-Improvement. 
Table 3. Treatment-Emergent Adverse Events During the Open-Label Phase ( $>5 \%$ ), ENRolled Safety Population

\begin{tabular}{lc}
\hline & $\begin{array}{c}\text { 8-week open label } \\
(\mathrm{n}=105)\end{array}$ \\
\cline { 2 - 2 } Adverse event & $\mathrm{n}(\%)$ \\
\hline Any TEAE & $69(65.7)$ \\
Decreased appetite & $29(27.6)$ \\
Upper abdominal pain & $15(14.3)$ \\
Irritability & $15(14.3)$ \\
Headache & $14(13.3)$ \\
Upper respiratory tract infection & $11(10.5)$ \\
Fatigue & $10(9.5)$ \\
Tachycardia & $9(8.6)$ \\
Insomnia & $7(6.7)$ \\
Dry mouth & $6(5.7)$ \\
Nausea & $6(5.7)$ \\
Vomiting & $6(5.7)$ \\
Affect lability & $6(5.7)$ \\
\hline
\end{tabular}

TEAE, treatment-emergent adverse event.

safety population, but all TEAEs occurred at frequencies of $\leq 4.1 \%$ within each treatment group. Psychiatric disorders (including insomnia in $3.1 \%$ and dysphoria in $2.1 \%$ ) occurred in $7.2 \%$ of subjects when receiving R-AMPH during the double-blind phase and in none of the subjects when receiving placebo. During the doubleblind treatment phase, no severe TEAEs or serious adverse events

Table 4. Treatment-Emergent Adverse Events During the Double-Blind Crossover Treatment Phase FOR THE RANDOMized SAFETy Population

\begin{tabular}{|c|c|c|}
\hline & \multirow{2}{*}{$\frac{\begin{array}{c}R-A M P H \\
(\mathrm{n}=97)\end{array}}{\mathrm{n}(\%)}$} & \multirow{2}{*}{$\begin{array}{c}\begin{array}{c}\text { Placebo } \\
(\mathrm{n}=97)\end{array} \\
\mathrm{n}(\%)\end{array}$} \\
\hline & & \\
\hline Number of TEAEs reported & 34 & 14 \\
\hline $\begin{array}{l}\text { Number of subjects with any reported } \\
\text { TEAE }\end{array}$ & $21(21.6)$ & $14(14.4)$ \\
\hline $\begin{array}{l}\text { Number of treatment-related TEAEs } \\
\text { reported }\end{array}$ & 20 & 6 \\
\hline $\begin{array}{l}\text { Number of subjects with any reported } \\
\text { treatment-related TEAE }\end{array}$ & $10(10.3)$ & $6(6.2)$ \\
\hline Psychiatric disorders & $7(7.2)$ & 0 \\
\hline Insomnia & $3(3.1)$ & 0 \\
\hline Mood swings & $2(2.1)$ & 0 \\
\hline Gastrointestinal disorders & $4(4.1)$ & 0 \\
\hline Upper abdominal pain & $3(3.1)$ & 0 \\
\hline Metabolism and nutrition disorders & $4(4.1)$ & 0 \\
\hline Decreased appetite & $4(4.1)$ & 0 \\
\hline Infections and infestations & $3(3.1)$ & $4(4.1)$ \\
\hline Upper respiratory tract infection & $1(1.0)$ & $2(2.1)$ \\
\hline $\begin{array}{l}\text { Injury, poisoning, and procedural } \\
\text { complications }\end{array}$ & $3(3.1)$ & $2(2.1)$ \\
\hline Contusion & $2(2.1)$ & 0 \\
\hline Cardiac disorders & $2(2.1)$ & $3(3.1)$ \\
\hline Tachycardia & $2(2.1)$ & $3(3.1)$ \\
\hline Investigations & $2(2.1)$ & $1(1.0)$ \\
\hline Weight decreased & $2(2.1)$ & $1(1.0)$ \\
\hline
\end{tabular}

TEAEs, treatment-emergent adverse events. were reported, and no subject prematurely discontinued study drug due to a TEAE.

All subjects had clinically insignificant or normal findings at screening on hematology and chemistry parameters and physical examination. Evaluation of vital signs for the enrolled safety population during the open-label phase of the study showed a mean (SD) increase in systolic blood pressure from baseline to the final open-label visit of the study of 2.9 (8.98) $\mathrm{mmHg}$, a mean (SD) increase in diastolic blood pressure of $4.5(8.23) \mathrm{mmHg}$, and a mean (SD) increase in pulse rate of 6.7 (12.72) bpm. During the open-label phase, TEAEs related to vital signs were reported for two subjects-elevated heart rate in one instance and increased blood pressure in the other instance-with resolution in both cases. During the double-blind phase of the study, mean changes from baseline in systolic and diastolic blood pressure were similar when subjects were taking R-AMPH and when they were taking placebo. Eight subjects $(8.2 \%)$ while taking R-AMPH and three subject (3.1\%) while taking placebo had one systolic blood pressure measurement $>95$ th percentile; two subjects $(2.1 \%)$ while taking R-AMPH and two subjects (2.1\%) while taking placebo had one diastolic blood pressure measurement $>95$ th percentile. Mean changes in the pulse rate were minimal and highly variable $(0.3$ [13.23] bpm on R-AMPH and - 0.1 [14.15] bpm on placebo).

During the open-label phase for the enrolled safety population, three subjects scored positive at only one visit on at least one item in the "Suicidal Ideation" section of the C-SSRS. The first of these cases occurred with the subject's mother before the baseline visit and before the study medication was started, in a context of some continuing reaction to the previous death of the subject's dog; the investigator judged this incident as not representing suicidal ideation and not related to study medication. The second case occurred at the week 1 visit due to one fleeting reactive episode in the setting of the subject being upset for being disciplined for misbehavior at school; the investigator judged this incident as being not related to the study medication and not representing an ongoing suicide risk that would prevent the subject from completing the study. In the third case, registered at the week 3 visit, the subject reported that he had said that he "wished that he were dead" for a few minutes after his girlfriend broke up with him. Upon further query, he reported that he did not want to die-he was just very upset. Another subject reported "nonsuicidal self-injurious behavior" at the week 4 visit. He hit himself in the face causing his nose to bleed briefly because he did not want to do homework. None of these occurrences was thought to be related to the study drug, and none resulted in subject discontinuation. The episodes were brief, had resolved before the visit during which they were reported, and were judged as not likely to recur. No occurrences of suicidal ideation or behavior were reported during double-blind treatment for the randomized safety population.

\section{Discussion}

In this first formal classroom study of racemic amphetamine (1:1 D-amphetamine to L-amphetamine), the primary objective was to establish that an optimal dose of R-AMPH would result in significant reduction in the signs and symptoms of ADHD in children aged 6-12 years while characterizing the onset of effect and duration of action as well as the side-effect profile for the medication. The primary efficacy variable, the mean SKAMP-Combined score at 2 hours postdose, was significantly lower ( -7.9 points, $p<0.0001$ ) for subjects on R-AMPH compared to placebo during the double-blind laboratory classroom phase of the study, and the 
mean change at 2 hours from predose SKAMP scores was significantly greater. Changes in the SKAMP-Attention and SKAMPDeportment subscales were also significant at 2 hours postdose ( $p<0.0001)$ favoring R-AMPH compared to placebo.

SKAMP-Combined scores, SKAMP-Attention subscale scores, and SKAMP-Deportment subscale scores were significantly improved at each time point tested when subjects were taking RAMPH versus placebo, with onset of action by the first time point tested, 0.75 hour postdose, and with efficacy persisting to the last time point measured (10 hours). The greatest R-AMPH effect compared to placebo was seen at 4 hours postdose, and the greatest change from the predose score was seen at 2 hours postdose. When subjects were taking R-AMPH, they also had significantly improved $(p<0.0001)$ PERMP scores compared to placebo at each time point tested through 10 hours, attempting more problems and answering more questions correctly.

The findings regarding the time to onset and duration of effect for a single dose of immediate-release R-AMPH can be contextualized with reference to an earlier pharmacokinetic/pharmacodynamic study of Adderall immediate-release mixed amphetamine salts (MAS, 3:1 D-amphetamine to L-amphetamine) in a laboratory classroom setting (Greenhill et al. 2003). Noting that a previous double-blind, crossover dose-comparison laboratory school study found that higher once-daily doses of extended-release MAS increased duration of action (from 3.5 to 6.4 hours) at the expense of a delay in the time of peak effect (from 1.5 to 3.0 hours) (Swanson et al. 1998), Greenhill et al. (2003) tested the effect of twice-daily $10 \mathrm{mg}$ immediate-release MAS compared to the once-daily 20-mg dosing and confirmed that the biphasic release of equal amounts of amphetamine 4 hours apart was more effective in controlling behavior and improving performance over the course of an entire school day. The findings in the study by Greenhill et al. (2003) supported the development of the once-daily extended release formulation of MAS. In comparison, the duration of action in this trial was 9.25 hours for the single-dose R-AMPH compared with $\sim 6$ hours at best for MAS.

During the 8-week open-label dose-optimization phase, disease status steadily improved, as measured by the CGI-S scale for disease severity and the CGI-I scale for disease improvement. By the end of the open-label treatment, $33.0 \%$ of subjects were "normal, not at all ill" and only $3.1 \%$ remained "moderately ill," while $94.8 \%$ were "much" or "very much" improved. Mean changes from baseline in the ADHD-RS-IV scale showed improvement of ADHD symptoms at each visit through the 8 weeks, and at the week 8 visit, $87.6 \%$ of subjects were considered "responders" in having an improvement from baseline of $\geq 50 \%$ on this scale.

The TEAEs in both the open-label and double-blind phases of the trial were similar to those reported in other studies of stimulant use in the school-age population (Biederman et al. 2002; Robb et al. 2014). Overall, there were small mean increases in blood pressure and pulse. During the double-blind phase, one systolic blood pressure measurement $>95$ th percentile was reported for $8.2 \%$ of subjects while taking R-AMPH and $3.1 \%$ while taking placebo; one diastolic blood pressure measurement $>95$ th percentile was reported for $2.1 \%$ while taking R-AMPH and $2.1 \%$ while taking placebo.

This racemic mixture delivers $\mathrm{D}$ - and $\mathrm{L}$-amphetamine isomers contributing equally toward potentiating norepinephrinergic, but not dopaminergic, neurotransmission in the prefrontal cortex (Heal et al. 2008). Prior research has demonstrated that the L-isomer is more balanced in terms of increases in extraneuronal concentrations of norepinephrine and striatal dopamine, while the D-isomer provides most of the increase in dopaminergic drive (Easton et al. 2007; Ghodse 2010). The L-isomer, however, is more potent than the D-isomer in cardiovascular activity, but less potent in causing central nervous system excitatory effects. It is also less effective as an appetite suppressant compared to dextroamphetamine (Arnold et al. 1972). As the other amphetamine products used to treat ADHD are D-isomer predominant, R-AMPH could exhibit a different sideeffect profile. During the open-label phase of this study, $27.6 \%$ of subjects experienced decreased appetite, $11.4 \%$ irritability, and $5.7 \%$ insomnia. With regard to cardiovascular changes, small mean increases in systolic $(2.9 \mathrm{mmHg})$ and diastolic $(4.5 \mathrm{mmHg})$ blood pressures were recorded during the open-label phase. However, comparative studies would be needed to show any differences compared to D-isomer predominant compounds. In addition, the L-isomer is known to have a longer half-life than the D-isomer. This property could help explain the finding of prolonged efficacy in this study with an immediate-release preparation of a 1:1 racemic mixture of $\mathrm{D}$ - and L-amphetamine after a single morning dose. R-AMPH demonstrated statistically significant efficacy for all time points from 0.75 hours to the last time point measured at 10 hours.

\section{Limitations}

This study excluded children with significant psychiatric and medical co-morbidities, which limits the generalizability of the results.

During the 8-week open-label dose-optimization phase of the trial, the dosing regimen was twice daily, with the first dose to be taken in the morning and the second dose to be taken 4-6 hours later. During the double-blind period, the dosing regimen was also twice daily, except for the 2 laboratory classroom days, on which only the single morning dose was administered (and not the second daily dose). The regimen of administering only the single morning dose on the laboratory classroom days was deliberately chosen to test the duration of action of R-AMPH. Consequently, the results reported for the laboratory classroom days might underrepresent the level of symptom control achieved during the open-label phase.

Trials that employ a crossover design, such as laboratory classroom studies, can be subject to both carryover and period effects. Differential carryover effects between treatments were analyzed by the statistical team, and none was reported that might affect the robustness of the statistical conclusions. A period effect could occur when a subject's performance in the second period of the crossover is affected by a change in mental or health status that has arisen independently of treatment. Because no treatment-byperiod interaction appeared to be present in the current study, separate analyses of the different periods of data were not conducted to confirm the results of the combined period data.

\section{Conclusions}

This placebo-controlled study demonstrated that an optimal dose of R-AMPH effected a significant reduction in the signs and symptoms of ADHD in children aged 6-12 years in a laboratory classroom setting. When receiving R-AMPH, compared to placebo, the children had a significant $(p<0.0001)$ mean reduction $(-7.9$ points) in the primary endpoint of SKAMP-Combined scores at 2 hours postdose and a significantly greater mean decrease (by 10.5 points, $p<0.0001)$ from their predose scores. R-AMPH significantly improved $(p<0.0001)$ SKAMP-Combined scores at each time point tested throughout the 10-hour laboratory classroom days, with effect onset 45 minutes postdose and extending to the last time point measured (10 hours). Also, the PERMP-A and PERMP-C 
throughout the 2 laboratory classroom days significantly improved ( $p<0.0001)$ while subjects were treated with R-AMPH. During the open-label phase, improvements were observed with R-AMPH in scores of the ADHD-RS-IV and the CGI-S and CGI-I scales. RAMPH was generally well tolerated, with an adverse-event profile and effects on heart rate and blood pressure similar to those observed with other amphetamine products in the pediatric ADHD population.

\section{Clinical Significance}

Results from this trial indicate that R-AMPH is effective in the treatment of ADHD in subjects 6-12 years of age when dosed once or twice daily. R-AMPH received FDA approval for treatment of ADHD in children $\geq 3$ years of age in September 2014 .

\section{Disclosures}

Dr. Childress has been a consultant, speaker, and research support for Ironshore Pharmaceuticals, Novartis Pharmaceuticals, Pfizer, Shionogi Pharma, and Shire Pharmaceuticals; a speaker and research support for Bristol-Myers Squibb; a consultant and research support for NextWave Pharmaceuticals, Neos Therapeutics, and Rhodes Pharmaceuticals; and a research support for Arbor Pharmaceuticals, Eli Lilly, Forest Research Institute, Johnson \& Johnson, Noven Pharmaceuticals, Neurovance, Otsuka Pharmaceutical, Purdue Pharma, Sunovion Pharmaceuticals, Therovance Biopharma, and Tris Pharma. Dr. Brams has been a speaker and research support for Otsuka Pharmaceuticals and Shire Pharmaceuticals; a speaker for Astra Zeneca and Sunovion Pharmaceuticals; and a research support for Arbor Pharmaceuticals. Dr. Cutler has been a consultant, speaker, and research support for AbbVie, Astra Zeneca, Janssen Pharmaceuticals, Eli Lilly, Novartis Pharmaceuticals, Otsuka Pharmaceutical, NextWave Pharmaceuticals, Shionogi Pharma, Shire Pharmaceuticals, and Sunovion Pharmaceuticals; and a consultant and research support for Akili Interactive, Arbor Pharmaceuticals, Johnson \& Johnson, Neos Therapeutics, Neurovance, Noven Pharmaceuticals, Purdue Pharma, Rhodes Pharmaceuticals, Supernus Pharmaceuticals, Targacept, and Therovance Biopharma. Dr. Kollins has been a consultant and/or research support for Akili Interactive, Alcobra Pharmaceuticals, Atentiv, Ironshore Pharmaceuticals, Arbor Pharmaceuticals, NEOS Pharmaceuticals, Purdue Canada, Rhodes Pharmaceuticals, Shire Pharmaceuticals, Sunovion Pharmaceuticals, and Tris Pharma. Dr. Northcutt has been a research support for Akili Interactive, Arbor Pharmaceuticals, Bristol-Myers Squibb, DART Neuroscience, Forest Laboratories, Noven Pharmaceuticals, Shionogi Pharma, Shire Pharmaceuticals, Sunovion Pharmaceuticals, and Supernus Pharamceuticals. Dr. Padilla has been a speaker and research support for Eli Lilly, Forest Laboratories, and Shire Pharmaceuticals; and a research support for Arbor Pharmaceuticals, Alcobra Pharma, Merck, Noven Pharmaceuticals, Pfizer, Purdue Pharma, Sunovion Pharmaceuticals, and Takeda Pharmaceutical. Dr. Turnbow has been a consultant and research support for Sunovion Pharmaceuticals; a consultant for Novartis Pharmaceuticals; and a research support for Arbor Pharmaceuticals, Concordia Pharmaceuticals, Purdue Pharma, Shionogi Pharma, and Shire Pharmaceuticals.

\section{References}

American Psychiatric Association. Diagnostic and Statistical Manual of Mental Disorders, 4th ed., Text Revision (DSM-IV-TR). Washington, DC: American Psychiatric Association; 2000.
American Psychiatric Association. Diagnostic and Statistical Manual of Mental Disorders. 5th ed. (DSM-5). Arlington, VA: American Psychiatric Association; 2013.

Arnold LE, Wender PH, McCloskey K, Snyder SH: Levoamphetamine and dextroamphetamine: Comparative efficacy in the hyperkinetic syndrome. Assessment by target symptoms. Arch Gen Psychiatry 27:816-822, 1972.

Barbaresi WJ, Katusic SK, Colligan RC, Weaver AL, Jacobsen SJ: Modifiers of long-term school outcomes for children with attentiondeficit/hyperactivity disorder: Does treatment with stimulant medication make a difference? Results from a population-based study. J Dev Behav Pediatr 28:274-287, 2007.

Biederman J, Lopez FA, Boellner SW, Chandler MC: A randomized, double-blind, placebo-controlled, parallel-group study of SLI381 (Adderall XR) in children with attention-deficit/hyperactivity disorder. Pediatrics 110:258-266, 2002.

Biederman J, Petty CR, Woodworth KY, Lomedico A, Hyder LL, Faraone SV: Adult outcome of attention-deficit/hyperactivity disorder: A controlled 16-year follow-up study. J Clin Psychiatry 73:941-950, 2012.

Busner J, Targum SD. The Clinical Global Impressions Scale: Applying a research tool in clinical practice. Psychiatry 4:28-37, 2007.

DuPaul G, Power T, Anastopoulos A, Reid R: ADHD Rating Scale IV: Checklists, Norms, and Clinical Interpretations. New York: Guildford, 1998.

Easton N, Steward C, Marshall F, Fone K, Marsden C: Effects of amphetamine isomers, methylphenidate and atomoxetine on synaptosomal and synaptic vesicle accumulation and release of dopamine and noradrenaline in vitro in the rat brain. Neuropharmacology 52:405-414, 2007.

Ghodse H: Ghodse's Drugs and Addictive Behavior: A Guide to Treatment. Cambridge, United Kingdom: Cambridge University Press; 2010.

Greenhill LL, Swanson JM, Steinhoff K, Fried J, Posner K, Lerner M, Wigal S, Clausen SB, Zhang Y, Tulloch S: A pharmacokinetic/ pharmacodynamic study comparing a single morning dose of Adderall to twice-daily dosing in children with ADHD. J Am Acad Child Adolesc Psychiatry 42:1234-1241, 2003.

Heal DJ, Smith SL, Gosden J, Nutt DJ: Amphetamine, past and present $-\mathrm{a}$ pharmacological and clinical perspective. J Psychopharmacol 27:479-496, 2013.

Heal DJ, Smith SL, Kulkarni RS, Rowley HL: New perspectives from microdialysis studies in freely-moving, spontaneously hypertensive rats on the pharmacology of drugs for the treatment of ADHD. Pharmacol Biochem Behav 90:184-197, 2008.

Hodgkins P, Shaw M, McCarthy S, Sallee FR: The pharmacology and clinical outcomes of amphetamines to treat ADHD: Does composition matter? CNS Drugs 26:245-268, 2012.

Pliszka S: Practice parameter for the assessment and treatment of children and adolescents with attention-deficit/hyperactivity disorder. J Am Acad Child Adolesc Psychiatry 46:894-921, 2007.

Robb AS, Findling RL, Childress AC, Berry SA, Belden HW, Wigal SB: Efficacy, safety, and tolerability of a novel methylphenidate extended-release oral suspension (MEROS) in ADHD. J Atten Disord 2014 doi: 10.1177/10870547/4533191. [Epub ahead of print].

Sagvolden T, Xu T: 1-Amphetamine improves poor sustained attention while d-amphetamine reduces overactivity and impulsiveness as well as improves sustained attention in an animal model of AttentionDeficit/Hyperactivity Disorder (ADHD). Behav Brain Funct 4:3, 2008.

Swanson JM, Wigal S, Greenhill LL, Browne R, Waslik B, Lerner M, Williams L, Flynn D, Agler D, Crowley K, Fineberg E, Baren M, Cantwell DP: Analog classroom assessment of Adderall in children with ADHD. J Am Acad Child Adolesc Psychiatry 37:519-526, 1998 . 
Visser SN, Danielson ML, Bitsko RH, Holbrook JR, Kogan MD, Ghandour RM, Perou R, Blumberg SJ: Trends in the parent-report of health care provider-diagnosed and medicated attention-deficit/ hyperactivity disorder: United States, 2003-2011. J Am Acad Child Adolesc Psychiatry 53:34-46.e32, 2014.

Wigal SB, Wigal TL: The laboratory school protocol: Its origin, use, and new applications. J Atten Disord 10:92-111, 2006.

Willcutt EG: The prevalence of DSM-IV attention-deficit/hyperactivity disorder: A meta-analytic review. Neurotherapeutics 9:490499, 2012.

Wolraich M, Brown L, Brown RT, DuPaul G, Earls M, Feldman HM, Ganiats TG, Kaplanek B, Meyer B, Perrin J, Pierce K, Reiff M, Stein MT, Visser S: ADHD: Clinical practice guideline for the diagnosis, evaluation, and treatment of attention-deficit/hyperactivity disorder in children and adolescents. Pediatrics 128:1007-1022, 2011 a.
Wolraich M, Brown L, Brown RT, DuPaul G, Earls M, Feldman HM, Ganiats TG, Kaplanek B, Meyer B, Perrin J, Pierce K, Reiff M, Stein MT, Visser S: Process of care supplemental appendix. ADHD: Clinical practice guideline for the diagnosis, evaluation, and treatment of attention-deficit/hyperactivity disorder in children and adolescents. Pediatrics 128:SI1-SI21, $2011 \mathrm{~b}$.

Address correspondence to:

Ann C. Childress, MD

Center for Psychiatry and Behavioral Medicine 7351 Prairie Falcon Road Suite 160

Las Vegas, NV 89128

E-mail: drann87@aol.com 